\title{
ANALISIS FORMULASI KEBIJAKAN PEMERINTAH DALAM MENJAGA STABILITAS HARGA PANGAN DI KABUPATEN PANGKEP
}

\author{
Analysis of Government Policy Formulation in Maintaining Food Price Stability in PangkeP Regency \\ Yulianthi $^{1}$, Juharni ${ }^{2}$, Nurkaidah ${ }^{2}$ \\ ${ }^{1}$ Dinas Ketahanan Pangan Kabupaten Pangkep \\ ${ }^{2}$ Program Studi Ilmu Administrasi Negara, Program Pascasarjana, Universitas Bosowa \\ Email: yulianthi@gmail.com \\ Diterima: 17 September 2021 \\ Dipublikasikan: 21 Desember 2021
}

\begin{abstract}
ABSTRAK
Tujuan dalam penelitian ini yaitu 1) untuk menganalisis formulasi kebijakan pemerintah dalam menjaga stabilitas harga pangan beras Kabupaten Pangkep. 2) Untuk menganalisis faktor penghambat dan pendukung dalam membuat formulasi kebijakan stabilitas harga pangan beras Kabupaten Pangkep. Metode penelitian ini menggunakan metode penelitian kualitatif dimaksudkan dapat menggali informasi sebanyak mungkin dari masalah penelitian. Hasil penelitian menunjukan bahwa 1) Formulasi kebijakan pemerintah dalam menjaga stabilitas harga pangan beras Kabupaten Pangkep bahwa ada kebijakan pemerintah dalam menjaga stabilitas harga pangan beras Kabupaten Pangkep, karena pihak dinas ketahanan pangan daerah kabupaten pangkep selalu mengkoordinasi dengan dinas ketahanan pangan provinsi dan juga selalu ada pengawasan dari dinas ketahanan pangan kabupaten pangkep terhadap pihak produsen atau penjual beras di pasar sentral pangkep dalam menjaga harga beras agar masyarakat tidak keberatan membeli beras, dan untuk sampai sekarang ini pihak produsen atau penjual mengikuti Pasal 56 UU No. 18 Tahun 2012 dan Peraturan Menteri Perdagangan Republik Indonesia Nomor 24 Tahun 2020 Tentang Penetapan Harga Pembelian Pemerintah Untuk Gabah Atau Beras pada pasal 3 ayat 1 poin c. 2) Faktor penghambat dan pendukung dalam membuat formulasi kebijakan stabilitas harga pangan beras Kabupaten Pangkep bahwa dari faktor penghambat pihak pemerintah masih berupayah agar gapoptan yang ada di kabupaten pangkep memiliki mesin penggiling yang menghasilkan beras premium untuk mengurangi dan membatasi pembeli gabah dari luar kabupaten pangkep faktor cuaca dan pupuk, karena cuaca sangat berpengaruh dalam mengeringkan gabah dan pada saat selesai menggiling gabah. faktor pendukung dalam penetapan harga pada tingkat produsen sebagai pedoman pembelian pemerintah sebesar Rp 8.300,00 yaitu operasional terhadap harga beras dan gabah meningkan maka pihak Dinas Bulog dan denas ketahanan panagan selalu melakukan pasar murah agar harga beras dan gabah turun, dengan cara mensterilkan harga beras dan gabah di kabupaten pangkep.
\end{abstract}

Kata Kunci: Kebijakan Stabilitas Harga Pangan Beras.

\begin{abstract}
The objectives of this study are 1) to analyze the formulation of government policies in maintaining the stability of food prices for rice in Pangkep Regency. 2) To analyze the inhibiting and supporting factors in formulating a policy for food price stability in Pangkep Regency. This research method using qualitative research methods is intended to be able to dig up as much information as possible from the research problem. The results showed that 1) The formulation of government policies in maintaining the stability of rice food prices in Pangkep Regency that there was a government policy in maintaining the stability of rice food prices in Pangkep Regency, because the Pangkep Regency regional food security service always coordinated with the provincial food security service and there was always supervision. from the Pangkep district food security service to rice producers or sellers in the Pangkep central market in maintaining rice prices so that people do not mind buying rice, and so far the producers or sellers have followed Article 56 of Law no. 18 of 2012 and Regulation of the Minister of Trade of the Republic of Indonesia Number 24 of 2020 concerning Determination of Government Purchase Prices for Grain or Rice in article 3 paragraph 1 point c. 2) The inhibiting and supporting factors in formulating the policy for food price stability in Pangkep Regency are that of the inhibiting factors, the government is still trying to ensure that Gapoptan in Pangkep Regency has a grinding machine that produces premium rice to reduce and limit unhulled buyers from outside Pangkep Regency. and fertilizers, because the weather is very influential in drying the grain and when finished grinding the grain. the supporting factor in determining the price at the producer level as a guide for government purchases of Rp. 8,300.00, namely the operation of increasing the price of rice and unhulled rice, the Bureau of Logistics and Food Security Denas always conduct a low-cost market so that the price of rice and unhulled rice decreases, by sterilizing the price of rice and rice. grain in Pangkep district.
\end{abstract}

Keywords: Rice Food Price Stability Policy.

This work is licensed under Creative Commons Attribution License 4.0 CC-BY International license

\section{PENDAHULUAN}

Pembukaan Undang-Undang Dasar Negara Republik Indonesia alinea IV menyatakan bahwa tujuan nasional
Indonesia adalah melindungi segenap bangsa Indonesia dan seluruh tumpah darah Indonesia, memajukan kesejahteraan umum, mencerdaskan kehidupan bangsa, 
dan ikut serta dalam kehidupan berbangsa dan bernegara. rakyat. Dalam pencapaian kemerdekaan, perdamaian abadi dan ketertiban dunia berdasarkan keadilan sosial. Salah satu tantangan dalam memajukan kesejahteraan masyarakat mungkin adalah pelaksanaan ketahanan pangan di Indonesia. Ketahanan pangan telah dinyatakan sebagai kondisi ketersediaan pangan nasional bagi perseorangan, memiliki pangan yang cukup dalam jumlah dan mutu, keamanan, keanekaragaman, gizi, pemerataan dan keterjangkauan, tidak sesuai dengan agama. Keyakinan dan budaya masyarakat, untuk hidup sehat, aktif dan produktif secara berkelanjutan. (Darmawangsa et al., 2018)

Salah satu dalam kebijakan pemerintah merupakan kebijakan stabilisasi harga pangan dan meminimalkan akibatnya terhadap inflasi. Stabilitas harga tidak cuma jadi atensi pemerintah dikala ini, namun pula di masa pemerintahan tadinya, paling utama semenjak berawalnya. Dikala ini, sistem perdagangan pangan dunia yang terus menjadi terbuka ataupun pasar leluasa menimbulkan produk pangan di dalam negara susah terkendalikan selaku akibat tranmisi dari suasana serta keadaan harga internasional. Keadaan ini dan bermacam kasus di dalam negara semacam penciptaan serta distribusi menimbulkan harga pangan paling utama bahan kebutuhan pangan pokok semacam beras, kedelai, daging ayam, cabai serta bawang merah jadi berfluktuasi. Tidak hanya itu, secara tahunan momen hari besar keagamaan nasional( HBKN) menimbulkan terdapatnya spekulasi harga yang menimbulkan harga bahan kebutuhan pangan pokok tiap tahun cenderung naik. Secara teori, harga produk pertanian spesialnya produk pangan didetetapkan oleh pasokan( lokal ataupun impor), permintaan, suasana harga pangan di pasar internasional dan ekspektasi warga. (Perdagangan, 2015).

Pangan ialah komoditas strategis yang kerap berhubungan dengan permasalahan ekonomi serta politik di Indonesia. Perihal ini disebabkan santapan ialah kebutuhan dasar manusia buat mempertahankan hidupnya. Oleh sebab itu, ialah hak asasi manusia buat penuhi kebutuhan pangan seluruh orang tiap dikala, yang membutuhkan pelaksanaan kontrol harga langsung buat melindungi pasar lokal dari pengaruh fluktuasi harga di pasar, pasar dunia serta aspek yang lain. Perihal ini bisa pengaruhi harga lokal serta oleh sebab itu permintaan lokal, sebab beras bisa dipertahankan serta santapan ialah kebutuhan dasar manusia. Ketidakmampuan warga buat penuhi kebutuhannya jadi ancaman untuk negeri sebab pada hakikatnya manusia hendak berperan dengan metode yang berbeda buat penuhi kebutuhannya. Kehancuran area, konversi lahan, harga bahan bakar fosil yang besar serta pergantian hawa sudah menimbulkan penyusutan lahan pertanian. Berkurangnya lahan pertanian jadi pemicu berkurangnya penciptaan pangan, yang pada kesimpulannya berakibat pada ketahanan pangan negeri. Bersamaan bertambahnya populasi, negeri memerlukan santapan bonus buat tingkatkan ketergantungan pangan antar negeri. terus tumbuh. Dikira selaku santapan pokok tiap hari cocok dengan kemampuan sumber energi serta kearifan lokal, santapan merupakan tipe santapan yang biasa dimakan oleh warga di negara- negara Asia. Dengan demikian, kondisi panen serta harga beras senantiasa jadi atensi pemerintah, sebab hendak berakibat pada negeri serta warga. (Darmawangsa et al., 2018).

Kabupaten Pangkep adalah salah satu kabupaten dengan harga pangan yang diperhatikan. Distribusi bahan pangan di kabupaten Pangkep berpusat pada lima Pasar utama yaitu pasar Pangkajene, Pasar Labbakang, Pasar Ma'rang, Pasar Sageri, dan Pasar Kalibone. Jenis pangan yang terdistribusi di kabupaten pangkep yaitu Beras (premium, medium, dan murah), minyak goring (curah dan bimoli), Gula pasir (Gulaku, dan Lokal), terigu (lokal dan kompas), daging sapi murni, daging ayam ras, telur ayam ras, cabe (merah besar, merah keriting, dan rawit), Bawang (merah, dan putih), kacang tahan, kedelai, ubi (kayu dan jalar), dan jabung (DKP Kab Pangkep, 2018). Akan tetapi studi penelitian berpusat pada pasar sentral pangkep sebagai tolak ukur atau mewakili pasar-pasar yang berada pada kabupaten pangkep dan pangan yang dimaksud dalam penelitian ini yaitu beras (DKP Kab Pangkep, 2019).

\section{METODE}

Metode penelitian yang digunakan adalah metode penelitian kualitatif. Teknik pengumpulan data dilakukan dengan metode observasi, wawancara, studi kepustakaan (Library Research), dan penelusuran data online. Metode pengumpulan informasi dicoba dengan observasi, wawancara, riset pustaka serta temu kembali informasi secara online. Tata cara analisis informasi survei ini merupakan tata cara analisis informasi deskriptif, ialah informasi diseleksi dengan memakai informasi primer serta sekunder yang dikumpulkan serta dikumpulkan, serta disimpulkan selaku jawaban atas persoalan yang lagi dipertimbangkan. Pengolahan informasi dicoba lewat reduksi informasi, penyajian informasi, penarikan kesimpulan serta validasi informasi. Sebaliknya reliabilitas informasi dalam riset ini diperoleh dengan memperluas pengamatan, tingkatkan intensitas, mempartisi informasi, menganalisis permasalahan negatif serta memakai rujukan.

\section{HASIL DAN PEMBAHASAN}

Perumusan kebijakan pemerintah dalam melindungi stabilitas harga pangan beras Kabupaten Pangkep serta Aspek penghambat serta pendukung dalam membuat perumusan kebijakan stabilitas harga pangan beras Kabupaten Pangkep lewat kebijakan stabilitas harga pangan beras di Kabupaten Pangkep dengan memakai penanda yang sudah disepakati bersama ialah penetapan harga pada tingkatan produsen selaku pedoman pembelian pemerintah sebesar $\mathrm{Rp}$ 8. 300, 00. Produsen yang di iktikad dalam riset ini ialah Petani serta Pelakon usaha pangan beras serta penetapan harga pada tingkatan 
konsumen selaku pedoman untuk penjualan Pemerintah sebesar Rp 8. 300, 00. Konsumen yang di iktikad dalam riset ini ialah orang yang membeli beras buat disantap.

\section{Formulasi Kebijakan Pemerintah Dalam Menjaga Stabilitas Harga Pangan Beras Kabupaten Pangkep}

Dalam perumusan kebijakan pemerintah dalam melindungi stabilitas harga pangan beras Kabupaten Pangkep bisa diukur lewat indiktor yang telah disepakati. penanda ini mengacu pada Pasal 56 UU Nomor. 18 Tahun 2012 serta Peraturan Menteri Perdagangan Republik Indonesia No 24 Tahun 2020 Tentang Penetapan Harga Pembelian Pemerintah Buat Gabah Ataupun Beras pada pasal 3 ayat 1 poin $\mathrm{c}$ ialah: Penetapan harga pada tingkatan produsen selaku pedoman pembelian Pemerintah; serta Penetapan harga pada tingkatan konsumen selaku pedoman untuk penjualan Pemerintah.

a. Penetapan Harga Pada Tingkat Produsen Sebagai

Pedoman Pembelian Pemerintah Sebesar Rp

$8.300,00$

Kebijakan pemerintah dalam melindungi stabilitas harga pangan beras Kabupaten Pangkep supaya penetapan harga pada tingkatan produsen selaku pedoman pembelian Pemerintah sebesar Rp 8. 300, 00. Produsen yang di iktikad dalam riset ini ialah Petani serta Pelakon usaha pangan beras. Dalam riset ini periset hendak menguraikan apa usaha yang dicoba Dinas ketahanan pangan buat mengatur serta melindungi stabilitas harga pangan beras Kabupaten Pangkep yang didapatkan lewat wawancara langsung di Dinas ketahanan pangan.

Bersumber pada hasil wawancara membuktikan kalau dalam penetapan harga pada tingkatan produsen selaku pedoman pembelian Pemerintah membuktikan kalau terdapatnya kebijakan pemerintah dalam melindungi stabilitas harga pangan beras Kabupaten Pangkep, dilihat dari dinas ketahanan pangan kabupaten senantiasa melaksanakan sosialisasi serta pembedahan pasar di kabupaten pangkep serta pihak dinas melaksanakan koordinasi dengan dinas terpaut serta dinas ketahanan pangan propinsi. Pihak ketahanan pangan kabupaten pangkep senantiasa melaksanakan pengawasan terhadap pihak produsen ataupun penjual beras di pasar sentral pangkep dalam melindungi harga beras supaya warga tidak keberatan membeli beras, serta buat hingga saat ini ini pihak produsen ataupun penjual menjajaki Peraturan Menteri Perdagangan Republik Indonesia No 24 Tahun 2020 Tentang Penetapan Harga Pembelian Pemerintah Buat Gabah Ataupun Beras tersebut. Sebaliknya buat saat ini ini pihak pembeli ataupun konsumen tidak keberatan sebab pihak konsumen dalm perihal ini membeli beras buat di mengkonsumsi tidak memandang dari harga beras, serta pihak produsen dalam perihal ini penjual beras menjual beras dengan harga bermacam- macam. Hendak namun perihal yang butuh dicermati serta diperbaiki semacam mutu pelayanan dari pihak bulog terhadap penggiling beras beras ataupun petani supaya tidak merasa keberatan dalam menjual beras kepada pemerintah, karena dengan minimnya mutu pelayanan dari pemerintah dapat pengaruhi minimnya atensi serta semangat petani ataupun penggiling menjual hasil kepada pemerintah.

b. Penetapan Harga Pada Tingkat Konsumen Sebagai Pedoman Bagi Penjualan Pemerintah Sebesar Rp 8.300,00.

Penetapan harga pada tingkatan konsumen selaku pedoman untuk penjualan Pemerintah supaya harga beras di pasar sentral pangkep mengacu pada Pasal 56 UU Nomor. 18 Tahun 2012 serta Peraturan Menteri Perdagangan Republik Indonesia No 24 Tahun 2020 Tentang Penetapan Harga Pembelian Pemerintah Buat Gabah Ataupun Beras pada pasal 3 ayat 1 poin Kebijakan harga beras ialah salah satu instrumen terutama dalam totalitas kebijakan. Uraian atas dinamika pergantian kebijakan yang diambil oleh tiap masa pemerintahan dan akibatnya untuk penyediaan pangan pokok beras ialah kekayaan pengetahuan dalam upaya menguasai totalitas kebijakan pangan serta ketahanan pangan.

Dalam perdagangan pastinya memiliki saluran distribusi benda. Begitu pula dengan beras. Beras ialah zona perdagangan yang menjanjikan. Sebab beras ialah salah satu kebutuhan pokok buat warga di Indonesia. Oleh karena itu butuh terdapatnya penetapan harga pada tingkatan konsumen selaku pedoman untuk penjualan pemerintah. Sehingga dengan terdapatnya penetapan harga beras dipasar supaya masyaraka tidak keberatan ataupun menyelahkan pada pemerintah, sebab penetapan harga pangan beras ialah bagian dalam mensejahteraan warga paling utama warga yang terletak di kabupaten pangkep.

Bersumber pada hasil wawancara bisa disimpulkan kalau pemerintah dalam perihal ini dinas ketahanan pangan kabupaten pangkep sudah melakukan penetapan harga pada tingkatan konsumen selaku pedoman untuk penjualan pemerintah sebesar Rp 8. 300, 00 di kabupaten Pangkep dilihat dari harga beras medium sebesar Rp. 8 . 000 hingga Rp. 9. 000 di pasar, sebab penjual membeli bers medium di penggiling( gapoptan) dengan harga $\mathrm{Rp}$. 7. 000 hingga Rp. 8. 000. sebab gapoptan yang menghasilkan beras ke TTI dalam perihal ini mitra tani sehingga harga beras dipasar sentral sama, tidak terdapat persaingan harga didalam pasar sentral pangkep. Sebaliknya buat beras premium di pasar dengan harga Rp. 10. 000 hingga Rp. 11. 000, sebab beras premium tidak dibuat di kabupaten pangkep sehingga penjual beras wajib membeli beras premium di luar kabupaten, sehingga harga beras premium berbeda dengan beras medium. Perihal yang butuh di perhatikan pemerintah buat menyetakan harga beras premium serta beras medium di pasar, pemerintah lekas mengadakan mesin pengiling yang dapat memproduksi beras premium supaya bisa menjauhi perbandingan harga tersebut.

Lampiran Peraturan Menteri Perdagangan Republik Indonesia Nomor 57/M-DAG/PER/8/2017 tentang penetapan harga eceran tertinggi beras pada tabel berikut: 
Tabel 1. Penetapan Harga Eceran Tertinggi Beras

\begin{tabular}{|c|c|c|c|}
\hline No & Wilayah & $\begin{array}{c}\text { HET } \\
\text { Medium } \\
(\mathrm{Rp} / \mathrm{Kg})\end{array}$ & $\begin{array}{c}\text { HET } \\
\text { Premium } \\
(\mathrm{Rp} / \mathrm{Kg})\end{array}$ \\
\hline 1 & $\begin{array}{lll}\text { Jawa, Lampung, } & \text { dan } \\
\text { Sumatera Selatan } & \end{array}$ & 9.450 & 12.800 \\
\hline 2 & $\begin{array}{l}\text { Sumatera kecuali Lampung, } \\
\text { dan Sumatera Selatan }\end{array}$ & 9.950 & 13.300 \\
\hline 3 & $\begin{array}{l}\text { Bali dan Nusa Tenggara } \\
\text { Barat }\end{array}$ & 9.450 & 12.800 \\
\hline 4 & Nusa Tenggara Timur & 9.950 & 13.300 \\
\hline 5 & Sulawesi & 9.450 & 12.800 \\
\hline 6 & Kalimantan & 9.950 & 13.300 \\
\hline 7 & Maluku & 10.250 & 13.600 \\
\hline 8 & Papua & 10.250 & 13.600 \\
\hline
\end{tabular}

Sumber: lampiran Peraturan Menteri Perdagangan Republik Indonesia Nomor 57/M-DAG/PER/8/2017.

Sedangkan indikator kinerja OPD yang mengacu pada tujuan dan sasaran RPJMD Kabupaten Pangkep dapat di lihat pada tabel berikut:

Tabel 2 Indikator Kinerja OPD Yang Mengacu Pada Tujuan Dan Sasaran RPJMD

\begin{tabular}{|c|c|c|c|c|c|c|c|c|}
\hline \multirow{2}{*}{ No } & \multirow{2}{*}{ Indikator } & $\begin{array}{l}\text { Kondi } \\
\text { si } \\
\text { kinerj } \\
\text { a pada }\end{array}$ & \multicolumn{5}{|c|}{ Target Capaian Setiap Tahun } & \multirow{2}{*}{ 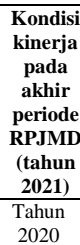 } \\
\hline & & $\begin{array}{c}\text { Tahun } \\
2015\end{array}$ & $\begin{array}{c}\text { Tahun } \\
2016\end{array}$ & $\begin{array}{l}\text { Tahun } \\
2017\end{array}$ & $\begin{array}{c}\text { Tahun } \\
2018\end{array}$ & $\begin{array}{c}\text { Tahun } \\
2018\end{array}$ & $\begin{array}{c}\text { Tahun } \\
2019\end{array}$ & \\
\hline (1) & (2) & (3) & (4) & (5) & (6) & (7) & (8) & (9) \\
\hline 1 & $\begin{array}{l}\text { Persentase } \\
\text { ketersediaan } \\
\text { pangan pokok }\end{array}$ & $5 \%$ & $5 \%$ & $5 \%$ & $5 \%$ & $5 \%$ & $5 \%$ & $5 \%$ \\
\hline 2 & $\begin{array}{l}\text { Persentase } \\
\text { penduduk } \\
\text { rawan yang } \\
\text { diintervensi }\end{array}$ & $0,10 \%$ & $0,10 \%$ & $0,10 \%$ & $0,10 \%$ & $0,10 \%$ & $0,10 \%$ & $0,10 \%$ \\
\hline 3 & $\begin{array}{l}\text { Capaian skor } \\
\text { pola pangan } \\
\text { harapan }(\mathrm{PPH})\end{array}$ & 84,7 & 86,8 & 88,3 & 90,1 & 91,9 & 93,7 & 95 \\
\hline \multirow[t]{2}{*}{4} & $\begin{array}{l}\text { Harga gabah di } \\
\text { tingkat } \\
\text { produsen sesuai } \\
\text { dengan harga } \\
\text { yang ditetapkan } \\
\text { pemerintah } \\
\text { (HPP) }\end{array}$ & $100 \%$ & $100 \%$ & $100 \%$ & $100 \%$ & $100 \%$ & $100 \%$ & $100 \%$ \\
\hline & $\begin{array}{l}\text { Persentase } \\
\text { gejolak harga } \\
\text { beras di tingkat } \\
\text { konsumen } \\
\text { berada dibawah } \\
25 \%\end{array}$ & $100 \%$ & $100 \%$ & $100 \%$ & $100 \%$ & $100 \%$ & $100 \%$ & $100 \%$ \\
\hline 5 & $\begin{array}{l}\text { Persentase } \\
\text { sampel di uji } \\
\text { yang berada di } \\
\text { bawah ambang } \\
\text { batas } \\
\text { maksimum } \\
\text { residu (BMR) }\end{array}$ & $90 \%$ & $92 \%$ & $93 \%$ & $93 \%$ & $93 \%$ & $93 \%$ & $93 \%$ \\
\hline
\end{tabular}

Sumber: Dinas Ketahanan Pangan Kabupaten Pangkep

Faktor penghambat dan pendukung dalam membuat formulasi kebijakan stabilitas harga pangan beras Kabupaten Pangkep

Faktor penghambat dan pendukung dalam membuat formulasi kebijakan stabilitas harga pangan beras Kabupaten Pangkep mengacu pada Pasal 56 UU No. 18 Tahun 2012 dan Peraturan Menteri Perdagangan Republik Indonesia Nomor 24 Tahun 2020 Tentang Penetapan
Harga Pembelian Pemerintah Untuk Gabah Atau Beras pada pasal 3 ayat 1 poin c. Adapun indikator untuk mengukur faktor penghambat dan pendukung dalam membuat formulasi kebijakan stabilitas harga pangan beras Kabupaten Pangkep yaitu sebagai berikut:

a. Penetapan harga pada tingkat produsen sebagai pedoman pembelian Pemerintah sebesar Rp $8.300,00$.

Faktor penghambat dan pendukung dalam membuat formulasi kebijakan stabilitas harga pangan beras Kabupaten Pangkep dalam penetapan harga pada tingkat produsen sebagai pedoman pembelian pemerintah sebesar Rp 8.300,00. Karena melaksanakan suatu program selalu adanya penghambat dan pendukung.

Berdasarkan hasil wawancara peneliti dapat simpulkan bahwa faktor penghambat dan pendukung dalam membuat formulasi kebijakan stabilitas harga pangan beras Kabupaten Pangkep. Dari faktor penghambat dalam penetapan harga pada tingkat produsen sebagai pedoman pembelian pemerintah sebesar Rp 8.300,00 yaitu pihak pemerintah masih berupayah agar gapoptan yang ada di kabupaten pangkep memiliki mesin penggiling yang menghasilkan beras premium untuk mengurangi dan membatasi pembeli gabah dari luar kabupaten pangkep faktor cuaca dan pupuk, karena cuaca sangat berpengaruh dalam mengeringkan gabah dan pada saat selesai menggiling gabah, hal ini jua sangat berpengaruh terhadap harga beras, karena kurangnya beras yang diproduksi sama halnya dengan pupuk, apabilah pupuk mahal di petani berarti harga beras juga naik, sehingga beras medium dan premium naik harga apabila kondisi cuaca dan pupuk yang dapat mempengaruhi harga, karna petani tidak bisa mengalami kerugian atas dasar pupuk yang mahal dan cuaca yang buruk mengakibatkan sebagian hasil panen gabah yang rusak, sehingga para petani menaikan harga gabah dan perubahan harga beras di pasar pun naik. Hal ini juga mengekibatkan kurangnya stok gabah sehingga harga beras naik di dalam daerah dan di luar daerah. Sedangkan faktor pendukung dalam penetapan harga pada tingkat produsen sebagai pedoman pembelian pemerintah sebesar Rp 8.300,00 yaitu operasional terhadap harga beras dan gabah meningkan maka pihak Dinas Bulog dan denas ketahanan panagan selalu melakukan pasar murah agar harga beras dan gabah turun, dengan cara mensterilkan harga beras dan gabah di kabupaten pangkep selalu melaksanakan atau membuat pasar murah agar bisa mensterilkan harga, pasar murah yang berlaku sambil mengamati harga beras dipasar sudah stabil. Dengan cara melaksanakan pasar mudah dapat juga mempengaruhui harga pangan beras dan gabah di pasar. Manfaat harga dasar yang diharapkan oleh petani adalah harga yang mampu melindungi petani dari melimpahnya produksi padi pada saat panen raya, bukan jaminan harga sepanjang tahun. Dengan kata lain, menilai keberhasilan operasi harga dasar berpijak pada kemampuan harga dasar menjamin harga sepanjang tahun kuranglah tepat. 
b. Penetapan harga pada tingkat konsumen sebagai pedoman bagi penjualan Pemerintah sebesar Rp $8.300,00$

Faktor penghambat dan pendukung dalam membuat formulasi kebijakan stabilitas harga pangan beras Kabupaten Pangkep yang dimaksud penetapan harga pada tingkat konsumen sebagai pedoman bagi penjualan Pemerintah sebesar Rp 8.300,00.

Dalam penetapan harga pada tingkat konsumen agar konsumen dalam hal ini pembeli beras yang akan di konsumsi. Karena tanpa adanya penetapan harga untuk konsumen bisa mengakibatkan kurangnya pembeli beras di pasar sentral pangkep.

Berdasarkan hasil wawancara peneliti dapat simpulkan bahwa faktor penghambat dan pendukung dalam membuat formulasi kebijakan stabilitas harga pangan beras Kabupaten Pangkep melalui penetapan harga pada tingkat konsumen sebagai pedoman bagi penjualan Pemerintah sebesar Rp 8.300,00 menunjukan bahwa dari pihak DPRD Kabupaten pangkep menyediakan transportasi yang mengangkut beras subsidi kepada masyarakat yang berada di kepulauan, dalam hal penetapan harga beras di pasar pihak anggota DPRD tidak berhak dan tidak memiliki wewenang dalam penetapan harga beras kepada konsumen atau masyarakat. Sedangkan kebijakan harga pangan beras dari penjual ke pembeli beras itu melalui gapoptan yang mengeluarkan beras ke TTI dalam hal ini mitra tani dimana ada harga pokok dari pemerintah bahwa beras sampai dipembeli seharga Rp.11.000 untuk premium dan harga Rp. 8.000 samapai Rp 9.000 untuk medium

\section{KESIMPULAN DAN SARAN}

Perumusan kebijakan pemerintah dalam melindungi stabilitas harga pangan beras Kabupaten Pangkep kalau terdapat kebijakan pemerintah dalam melindungi stabilitas harga pangan beras Kabupaten Pangkep, sebab pihak dinas ketahanan pangan wilayah kabupaten pangkep senantiasa mengkoordinasi dengan dinas ketahanan pangan provinsi serta pula senantiasa terdapat pengawasan dari dinas ketahanan pangan kabupaten pangkep terhadap pihak produsen ataupun penjual beras di pasar sentral pangkep dalam melindungi harga beras supaya warga tidak keberatan membeli beras, serta buat hingga saat ini ini pihak produsen ataupun penjual menjajaki Pasal 56 UU Nomor. 18 Tahun 2012 serta Peraturan Menteri Perdagangan Republik Indonesia No 24 Tahun 2020 Tentang Penetapan Harga Pembelian Pemerintah Buat Gabah Ataupun Beras pada pasal 3 ayat 1 poin $\mathrm{c}$.

Mekanisme sepanjang ini telah lumayan bagus serta efisien tetapi butuh penyempurnaan penerapan di lapangan cocok dengan keadaan area dan mengoptimalkan kedudukan Mitra Kerja. Pemerintah segerah megadakan mesin penggiling gabah yang menciptakan beras premium.

\section{DAFTAR PUSTAKA}

Abidin, S. Z. (2006). Kebijakan publik. Suara Bebas.

Agustino, L. (2008). Dasar-dasar kebijakan publik. Bandung: Alfabeta.

Amang, B., \& Sawit, M. H. (1999). Kebijakan Beras dan Pangan Nasional. Penerbit Institut Pertanian Bogor, Bogor.

Arjayanti, S. (2010). Analisis Kebijakan Stabilitas Harga Gabah/Beras di Tingkat Petani di Propinsi DIY. JKAP (Jurnal Kebijakan Dan Administrasi Publik), 14(2), 17-33.

Darmawangsa, A. R. P., Wahyudi, B., \& Supandi, S. (2018). Pelaksanaan Inpres Nomor 5 Tahun 2015 Dalam Menjaga Stabilitas Harga Beras Di Kabupaten Purworejo, Jawa Tengah. Ekonomi Pertahanan, 4(1).

Firdaus, M., Baga, L. M., \& Pratiwi, P. (2019). Swasembada Beras dari Masa ke masa. PT Penerbit IPB Press.

Hermanto, S. (n.d.). Kebijakan Harga Beras Ditinjau dari Dimensi Penentu Harga.

Islamy, I. (1997). Prinsip-Prinsip Perumusan Kebijakan publik. Bumi Aksara Jakarta.

Juharni. (2017). Manajemen Mutu Terpadu (Total Quality Management). CV Sah Media. Makassar.

Karsin, E. S. (2004). Klasifikasi Pangan dan Gizi. Pengantar Pangan Dan Gizi. Panebar Swadaya, Jakarta.

Laura, H., Brady, J., \& Judy, A. (1986). Pangan, Gizi, dan Pertanian. Jakarta Penerbit Universitas Indonesia.

Lokollo, E. M. (2015). Kebijakan harga serta dampaknya terhadap ketahanan pangan. E. Pasandaran, M. Rachmat, Hermanto, M. Ariani, Sumedi, K. SUradisastra, \& Haryono (Eds.), Memperkuat Kemampuan Swasembada Pangan, 192-202.

Mariska, M. (2016). Analisis Pengaruh Kebijakan Harga Pembelian Pemerintah Terhadap Permintaan Beras Di Kabupaten/Kota Provinsi Lampung Tahun 20092013.

Moleong, L. J. (2007). Metode penelitian kualitatif. Bandung: Remaja Rosdakarya.

Mukhlisin, Y., Imrona, M., \& Murdiansyah, D. T. (2020). Prediksi Harga Beras Premium Dengan Metode Algoritma K-nearest Neighbor. EProceedings of Engineering, 7(1).

Nugroho, R. (2003). Kebijakan publik: Formulasi, implementasi dan evaluasi. Jakarta: Elex Media Komputindo.

Perdagangan, K. (2015). Laporan Akhir Kajian Kebijakan Harga Pangan. Pusat Kebijakan Perdagangan Dalam Negeri Badan Pengkajian Dan Pengembangan Kebijakan Perdagangan Kementrian Perdagangan. Jakarta.

Putri, K. E. (2020). Implementasi peraturan menteri perdagangan Republik Indonesia nomor 35/MDAG/PER/7/2013 tentang pencantuman harga barang dan tarif jasa yang diperdagangkan oleh 
pelaku usaha dikota Pangkalpinang. Universitas Bangka Belitung.

Rachmat, M., Rachman, B., Kustiari, R., Supriyati, I., Budi, I. G. S., Wahyuning, I., MS, K. S., \& Hidayat, D. (n.d.). Sinergi Penelitian Dan Pengembangan Bidang Pertanian (SINTA).

Rahmat, P. S. (2009). Penelitian Kualitatif. In Journal Equilibrium.

Saragih, J. P. (2017). Kelembagaan Urusan Pangan dari Masa ke Masa dan Kebijakan Ketahanan Pangan. Jurnal Pangan, 26(1), 57-80.

Septiadi, D., Harianto, H., \& Suharno, S. (2016). Dampak Kebijakan Harga Beras dan Luas Areal Irigasi Terhadap Pengentasan Kemiskinan di Indonesia. Jurnal Agribisnis Indonesia, 4(2), 91-106.

Sudaryanto, T., \& Rachman, B. (2000). Arah Kebijakan Distribusi/Perdagangan Beras Dalam Mendukung Ketahanan Pangan. Distribusi/Perdagangan Luar Negeri, Semiloka Perberasan, Ditjen Tanaman Pangan Dan Hortikultura, Departemen Pertanian. Jakarta.

Sugiyono. (2012). Metode Penelitian Kuantitatif, Kualitatif dan R \& D.Bandung:Alfabeta. Metode Penelitian Kuantitatif, Kualitatif Dan R \& D.Bandung: $\quad$ Alfabeta. https://doi.org/10.1017/CBO9781107415324.004

Sugiyono. (2015). Metode Penelitian. Metode Penelitian.

Suharto, E. (2011). Kebijakan sosial. Bandung: Alfabeta.

Suharyanto, H. (2011). Ketahanan Pangan. Jurnal Sosial Humaniora (JSH), 4(2), 186-194.

Sukardi, W., \& Purwaningsih, I. (2008). Uji coba penggunaan inokulum tempe dari kapang Rhizopus oryzae dengan substrat tepung beras dan ubikayu pada unit produksi tempe Sanan Kodya Malang. Jurnal Teknologi Pertanian, 9(3), 207-215.

Syafiie, I. K., Modeong, S., \& Tanjung, J. (1994). Ilmu administrasi publik. Rineka Cipta.

Tangkilisan, H. N. S. (2003). Kebijakan publik yang membumi. Yogyakarta: Lukman Offset.

Winarno, B. (2002). Teori dan proses kebijakan publik. Media Pressindo.

Winarno, B. (2007). Kebijakan publik: Teori dan proses. Yogyakarta: Media Pressindo.

Yasin, S., \& Hapsoyo, S. (2008). Kamus Besar Bahasa Indonesia, Praktis, Populer dan Kosa Kata Baru. Surabaya: Mekar.

Yusuf, A. M. (2014). Metode Penelitian Kuantitatif, Kualitatif, dan Penelitian Gabungan, Jakarta: PT. Fajar Interpratama Mandiri 